\title{
A TALE OF CONTRASTING TRENDS: THREE MEASURES OF THE ECOLOGICAL FOOTPRINT IN CHINA, INDIA, JAPAN, AND THE UNITED STATES, 1961-2003
}

\author{
Richard York \\ Department of Sociology \\ University of Oregon \\ rfyork@uoregon.edu \\ Eugene A. Rosa \\ Department of Sociology \\ Washington State University \\ rosa@wsu.edu \\ Thomas Dietz \\ Environmental Science and Policy \\ Michigan State University \\ tdietz@msu.edu
}

\begin{abstract}
We assess threats to environmental sustainability by examining the trends in three measures of the ecological footprint (EF) - the total EF, the per capita $E F$, and the EF intensity of the economy (EF/GDP) - for China, India, Japan, and the United States. from 1961 to 2003. The EF, an estimate of the land area needed to sustain use of the environment, is the most comprehensive measure of anthropogenic pressure on the environment available and is growing in use. We argue that the total EF is the most relevant indicator for assessing threats to nature's capital and services, that per capita EF is the most relevant indicator of global inequalities, and that EF intensity is the most relevant indicator of economic benefits from environmental exploitation. We find in all four nations that the ecological intensity of the economy declined (i.e., efficiency improved) over this period, but the total national EF increased substantially. This is a demonstration of the Jevons paradox, where efficiency does not appear to reduce resource consumption, but rather escalates consumption thereby increasing threats to environmental sustainability.
\end{abstract}

\section{INTRODUCTION}

There is a considerable body of research in the world-systems literature examining the structural forces that influence national-level environmental impacts (e.g., Burns, Kick, and Davis 2003; Dietz and Rosa 1997; Dietz, Rosa, and York 2007; Jorgenson 2003; Jorgenson and Burns 2007; 
Jorgenson and Kick 2003; Jorgenson and Rice 2005; Roberts, Grimes, and Manale 2003; Rosa, York, and Dietz 2004; Rothman 1998; York 2007; York, Rosa, and Dietz 2003, 2004). The importance of tracking the environmental performance of nations is obvious in light of the myriad environmental problems around the globe: global warming, large-scale deforestation, desertification, loss of biodiversity, and disturbances to major geochemical cycles. A substantial variety of national-level environmental indicators have been examined in the environmental social science literature, but there is no consensus regarding which indicators are the most theoretically or substantively important. The reason for this is clear; different indicators reflect different aspects of the complex, hyper-faceted global ecology.

Our primary concern here is not with identifying which indicators are the "best" measures of human pressure on the environment, but with the proper matching of the form of the indicator - total national ecological consumption and/or pollution emissions, per capita ecological consumption and/or pollution emissions, or ecological consumption and/or pollution emissions per unit of GDP (the ecological intensity of the economy) - to various theoretical or substantive tasks. Here we use variations of the Ecological Footprint (EF) as our principal indicator for theoretical reasons explained below. Three EF variations (total, per capita, and intensity) tell fundamentally different stories about the environmental performance of nations, and it is, therefore, theoretically important to distinguish among these stories. To illustrate the differences among them, we examine temporal trends in the EF of each variation for four nations which account for a large share of the world's population, economic output, and natural resource consumption: China, India, Japan, and the United States. ${ }^{1}$ These four nations combined account for $45 \%$ of the total global EF, indicating that what happens in these nations is particularly important for the future well-being of the planet (Loh and Goldfinger 2006:3). We first explain the EF, the environmental indicator which is our focus here. We then present analyses of the trends in the EF in these four nations, with a discussion of the substantive and theoretical implications of these trends.

\section{THE ECOLOGICAL FOOTPRINT}

The EF, originated by Wackernagel and Rees (1996) and further developed by them and others (e.g., Chambers, Simmons, and Wackernagel 2000; Kitzes et al. 2007), is designed to assess the demands societies place on the regenerative capacity of the biosphere. The EF has been widely used in the field of ecology and in the environmental social sciences, and is generally regarded as a reliable indicator of anthropogenic pressure on the environment (Dietz et al. 2007; Jorgenson 2003; Jorgenson and Burns 2007; Jorgenson and Rice 2005; Rosa et al. 2004; Rothman 1998; York et al. 2003, 2004). The EF is calculated, much the same way that economic consumption is, by adding up the various forms of consumption in a society - food, housing, transportation,

\footnotetext{
${ }^{1}$ Based on the most recent year of the data we analyze here, the United States, China, and India have the three largest ecological footprints in the world (in that order) and Japan has the fifth largest, behind Russia. We do not examine Russia here since it has only been an independent nation since 1991. China, India, and the United States have the three largest populations in the world (in that order) and Japan has the ninth. The United States and Japan have the two largest economies in the world (in that order), China the fifth, and India the thirteenth.
} 
consumer goods, and services - and the waste they generate. That consumption, similar to economic accounting, is converted into a common metric. But unlike economics, which uses prices as its key indicator of value, the EF uses productive land area as its metric. The EF is based on the recognition that land is a fundamental factor on which all societies depend, since it provides living space, products and services, and a sink for wastes. Productive land is, therefore, a justifiable proxy for the demands societies place on the environment. The EF can be interpreted as a measure of the stress a nation places on natural capital and ecosystem services. The EF can be calculated for most nations because flows and consumption of resources and the production of wastes are typically recorded with reasonable accuracy in various national accounts. Human demands on the environment, then, can be converted into the biologically productive land areas necessary to provide these ecological services.

The EF is calculated by "adding up the areas (adjusted for their biological productivity) that are necessary to provide us with all the ecological services we consume" (Wackernagel et al. 1999:377). The EF is a fairly comprehensive indicator of human pressures on natural resources and ecosystem services, since it does not ignore tradeoffs among different types of environmental exploitation (e.g., wood vs. plastic consumption). National resource consumption is calculated by adding imports and subtracting exports from production.

Because of this matching of impact to locale of consumption, the EF accounting system is particularly suitable for world-systems analyses. World-systems theorists and other scholars have focused attention on how resource extraction and consumption, as well as pollution, are geographically distributed in the world-system, where the core nations commonly consume most of the resources, while the environmental degradation associated with resource extraction and polluting industries occurs in the periphery (Arrighi 2004; Brunnermeier and Levinson 2004; Bunker 1996; Frey 1998, 2003; Grimes and Kentor 2003; Hornborg 2003; Podobnik 2002). Due to its consumption-based focus, the EF does not overlook impacts that are externalized by moving production or extraction outside national borders. It, therefore, places environmental responsibility on the nations where resources are consumed - principally in the core - rather than on the ones where they are extracted.

The types of consumption delineated above are converted into the nine types of land area that support that consumption. All nine are aggregated to arrive at the total EF. The land area types are: (1) cropland, (2) grazing land, (3) forest (excluding fuel wood), (4) fishing ground, (5) built-up land, (6) the land area required to absorb carbon dioxide emissions from use of fossil fuel, (7) fuel wood, (8) hydro-power, and (9) nuclear power. The component EF measures are weighted to take into account the fact that different types of land vary in productivity. The weighting for each type of land is scaled to its productivity relative to the worldwide average productivity of all land (including water area). For example, consumption requiring one hectare of arable land would have an EF larger than consumption requiring one hectare of non-arable land, reflecting the high productivity of arable land relative to the average productivity of all land on Earth (Wackernagel et al. 2002:9268). Built-up land is treated as arable land since cities have historically grown in agriculturally rich areas. The hydro-power component is the area taken up by the reservoirs and infrastructure associated with hydro-electric dams. Each unit of energy from nuclear power is counted at par with one from fossil energy since analyses are inconclusive about the long-term land demands of nuclear power. We emphasize that the calculation of the EF for a nation is not based on its actual land area but on the land area that would be required, at global average productivities, to support its total consumption. Therefore, nations may, as many do, have 
footprints that are larger than their own land areas. The data in our analyses are from the Global Footprint Network (http://www.footprintnetwork.org/) 2006 Edition and were generously provided to us by Mathis Wackernagel and are used with his permission.

\section{UNDERSTANDING ENVIRONMENTAL TRENDS: NATIONAL CONSUMPTION, ECO-EFFICIENCY, AND INEQUALITY}

The foundational ecological economist William Stanley Jevons (2001 [1865]) identified an important paradox that, although becoming widely known today, still remains underappreciated. He noted, in the early days of England's industrial revolution, that the increasing efficiency of coal use in production was correlated with increasing, not decreasing, coal consumption. This is an observation of fundamental importance since it was commonly assumed then as now that technological improvements in the resource efficiency (eco-efficiency) of production (i.e., less energy and/or materials per unit of production) would typically lead to the conservation of natural resources (e.g., Hawken, Lovins, and Lovins 1999; Reijnders 1998). In short, if changes in the production system make it so that a given amount of output can be produced with fewer inputs, it seems "obvious" that the amount of inputs should decline. However, the amount of inputs often does not decline, but instead grows because the scale of production grows faster than efficiency improves. This is Jevons's insight, and it highlights the sharp distinction between efficiency in resource use and total resource consumption. These two different indicators give two different answers to the question of environmental performance, since the most "eco-efficient" businesses, industries, or economies may be the ones consuming the greatest quantities of resources and generating the most pollution. Jevons's observation raises the possibility that, far from actually contributing to resource conservation, improvements in efficiency in many contexts may actually induce the expansion of resource consumption (Clark and Foster 2001; York 2006; York and Rosa 2003).

The distinction between efficiency and total consumption is of particular relevance to theoretical debates over the effects of economic development and technological change on the environment. Some scholars uncritically assume that advances in the material and energy efficiency of economies (e.g., where more economic capital is generated per unit of energy and/or material consumption), which are often driven by technological refinements, are indicative of environmental improvements (Andersen 2002; Fan et al. 2007; Hawken et al. 1999). This assumption is invalid from the point of view of ecosystems and biophysical processes, since the amount of economic capital generated from exploiting the environment is a separate matter from the consequences of environmental exploitation for natural capital and services. Considerable empirical evidence shows that while low-income nations often are the least eco-efficient in the sense that they use a lot of resources or produce a lot of pollution per unit of GDP, they are also the nations that consume the least amount of resources in absolute and/or per capita terms (Roberts and Grimes 1997; York et al. 2003, 2004).

To illustrate the limitations of focusing on efficiency we turn to an examination of trends in the EF for China, India, Japan and the United States. In Figures 1-4 we present the trends over time in each of these nations in their total EF and their EF per unit of GDP. The latter measure we refer to as "intensity," which is the inverse of efficiency (i.e., high intensity means low efficiency). Strikingly, the trends in total EF and EF intensity illustrate how a focus on efficiency 
or intensity is misleading. In all nations there is a distinct trend toward declining intensity (i.e., increasing efficiency), which scholars might interpret as a sign of ecological improvements. After all, between 1961 and 2003 the EF per unit of GDP declined by a factor of 8.4, 3.2, 2.2, and 1.4 in China, India, Japan, and the United States respectively.

Figure 1

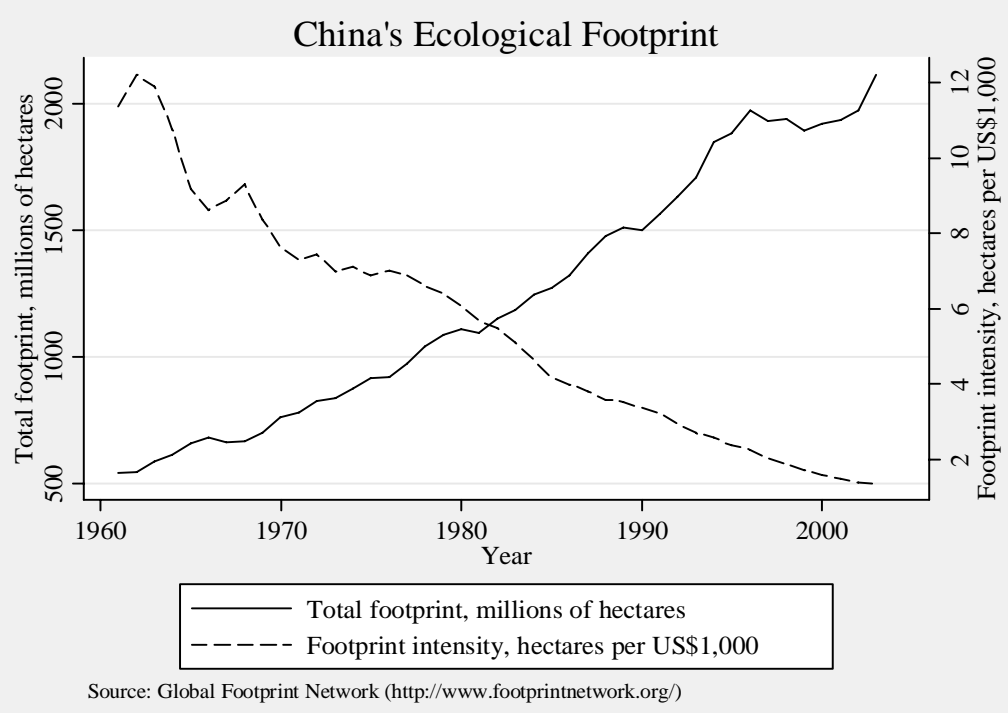

Figure 2

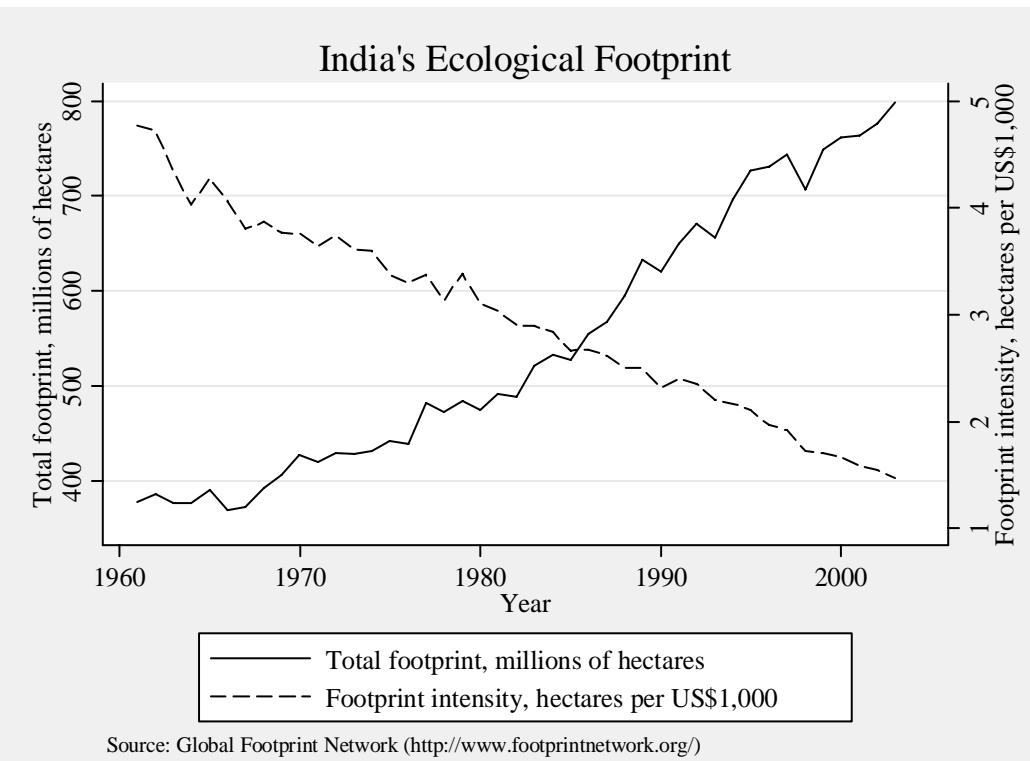


Figure 3

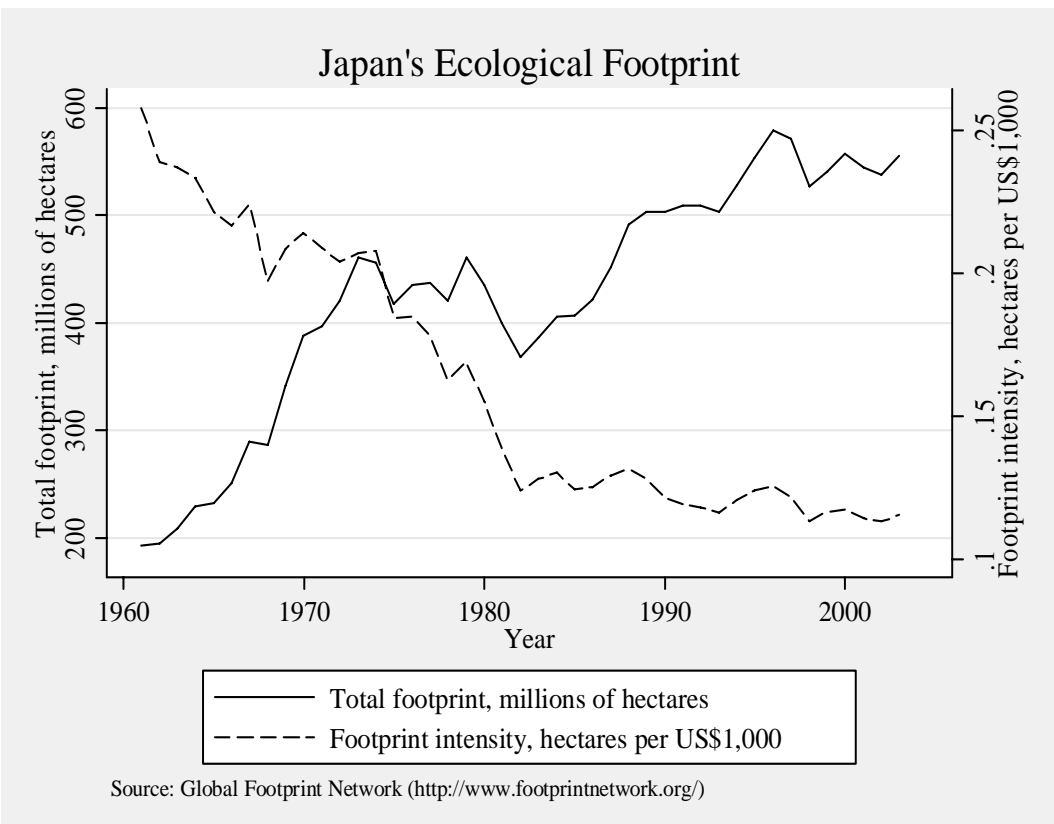

Figure 4

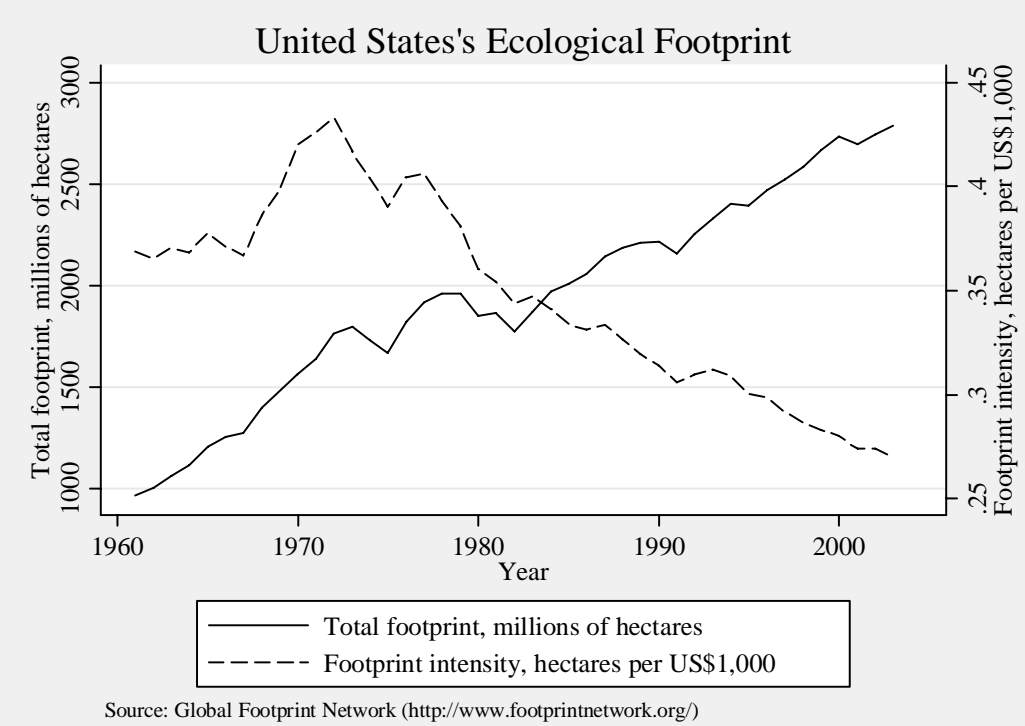

However, the ecologically relevant observation is that the total EF - which threatens nature's capital and services - increased quite dramatically in all of these nations over this period, by a factor of 3.9, 2.1, 2.9, and 2.9 in China, India, Japan, and the United States 
respectively. These findings indicate that all of these nations expanded their exploitation of the environment, while simultaneously expanding their economies even more. In other words, they used more resources while simultaneously getting more economic productivity out of each unit of resources. The improvements in efficiency (i.e., declines in intensity) were clearly associated not with reductions but, rather, with steady growth in resource consumption. The two trends are likely connected in a systemic way. Following the logic of Jevons's argument, a declining ratio of EF to economic activity often translates into lower costs per unit of production - since it typically indicates fewer inputs per unit of production - making it more affordable for producers to further expand production and thereby increase their profits. China's trajectory is particularly noteworthy, for it had both the largest improvement in efficiency over the period examined here, while exhibiting the greatest increase in its total EF. In light of these considerations, it might be more appropriate to say that improvements in efficiency are an example of economic reform not ecological reform and in fact typically indicate rising environmental impacts. Thus, total impact is the most informative measure from an ecological perspective because it signals threats to nature's capital and services. In contrast, efficiency or intensity is perhaps more informative from a profit-oriented perspective. At a deeper level this difference may reflect the differences in two accounting systems: an ecological accounting system where environmental factors are the primary concern and an economic accounting system where, as externalities, environmental consequences are typically ignored.

These observations generally counter the assumption of ecological modernization theory, a prominent theory in environmental sociology, that technological transformations are the key to solving our environmental problems. Ecological modernization theorist Maurie Cohen (1997:109) argues, for example, that, "a key element in executing this [the ecological modernization] transformation is a switchover to the use of cleaner, more efficient, and less resource intensive technologies..." Similarly, ecological modernization proponents Fisher and Freudenberg (2001: 702) and Milanez and Bührs (2007:572) agree that the "linchpin" of the ecological modernization argument is the assertion that technological improvements can solve environmental problems. Particularly noteworthy is Andersen's (2002:1404) statement: “Because ecological modernization by definition is linked with cleaner technology and structural change... we can take changes in the $\mathrm{CO}_{2}$ emissions relative to GDP as a rough indicator for the degree of ecological modernization that has taken place.” In light of the findings we present here, key assumptions in ecological modernization theory appear misguided.

A third way to measure human pressure on the environment is in per capita terms. Examining per capita resource consumption removes the effects of population, assuming consumption and emissions are scaled proportionally by population size. ${ }^{2}$ The per capita specification is perhaps most important from the perspective of global inequalities and social justice, since it allows for comparison of demands placed on the environment among the world's people and can highlight the substantial disparity in levels of consumption across nations. Figure 5 presents the trends in the EF per capita for the four nations examined here. Two observations stand out. First, while India's per capita EF stayed roughly constant from1961 to 2003, the per capita EF in each of the other three nations approximately doubled. Second, there is clearly stark inequality across nations in terms of per capita pressure on the environment. For example, in

\footnotetext{
${ }^{2}$ A series of analyses have found that the population elasticity of the EF is about 1.0 (Dietz et al. 2007; Rosa et al. 2004; York et al. 2003) thus justifying the use of per capita measures.
} 
2003 the EF per capita in the United States was approximately six times that of China and 13 times that of India. Thus, even though China and India each have very large and growing total footprints, it is clearly not because the typical person in each of those nations places a high demand on the environment relative to people in affluent nations.

Figure 5

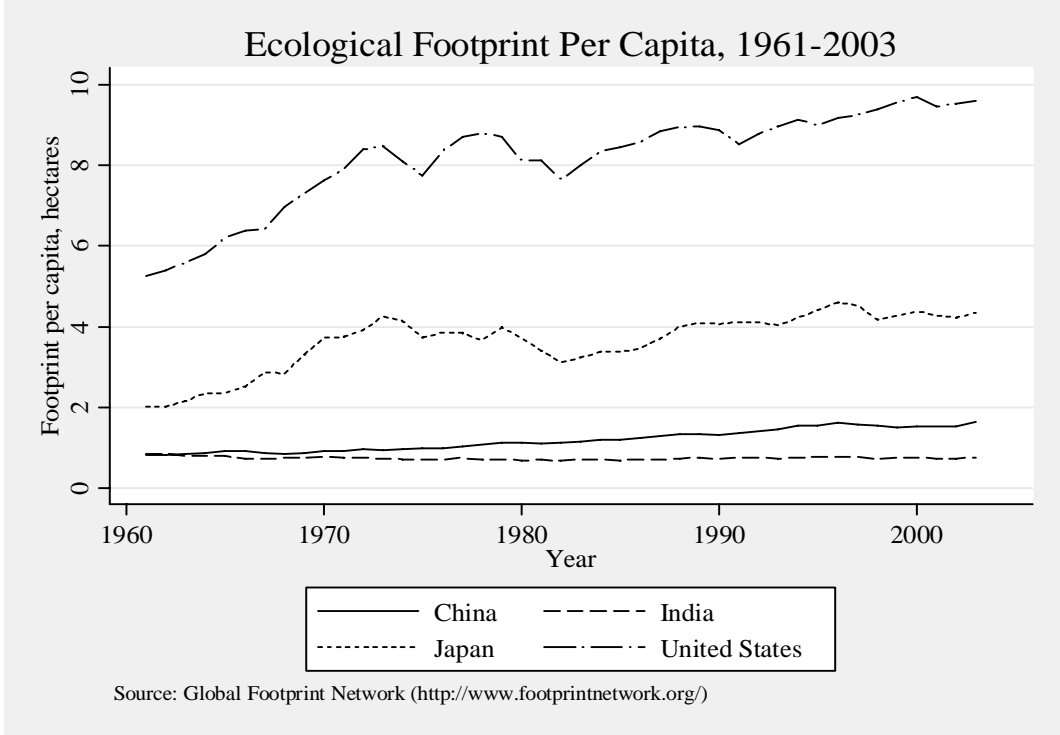

In 2003, the EF intensity in both China and India was over five times greater than in the United States and about 12 times greater than in Japan. If one focused on intensity, one would conclude that the United States and, particularly, Japan are good environmental stewards relative to the two larger, poorer nations, but this would mask the fact that the average person in the both the United States and Japan have a much greater effect on the environment than the average person in either China or India.

Table 1. Elasticity model of the ecological footprint regressed on GDP using the Prais-Winsten correction for first order auto-correlation for China, India, Japan, and the United States, 1961-2003.

$\begin{array}{lcccc} & \begin{array}{c}\text { China } \\ \text { Coef. (S.E.) }\end{array} & \begin{array}{c}\text { India } \\ \text { Coef. (S.E.) }\end{array} & \begin{array}{c}\text { Japan } \\ \text { Coef. (S.E.) }\end{array} & \begin{array}{c}\text { U.S. } \\ \text { Coef. (S.E.) }\end{array} \\ \mathbf{G D P} & .376(.026)^{*} & .430(.014)^{*} & .596(.067)^{*} & .878(.089)^{*} \\ \mathbf{R}^{2} & .999 & .999 & .998 & .998 \\ \mathbf{N} & 43 & 43 & 43 & 43\end{array}$

$* \mathrm{p}<.001$

Note: Ecological footprint and GDP are in natural logarithmic form. We do not report the y-intercepts. 
To further explore the connections between development and environmental degradation, we statistically analyzed the connection between economic production (GDP) and the EF. We estimated a Prais-Winsten time-series model correcting for first order autocorrelation for each of these nations and present the results in Table 1. Both GDP, measured in constant 2000 US\$ (World Bank 2005), and the EF were converted to natural logarithmic form for estimation purposes. The regression coefficient from the logged form has a straightforward interpretation in terms of elasticity; the coefficient indicates the percentage change in the EF for a $1 \%$ change in GDP. In all four nations the relationship between the GDP and EF is positive and inelastic (i.e., coefficients $>0$ and $<1$ ). This indicates that as the economy of each of these nations has grown, the EF has also grown but not as fast as the economy. This type of relationship is what generates the apparently paradoxical finding discussed above where efficiency improves while the total EF grows. If an inelastic relationship such as this is hypothetically maintained indefinitely, resource consumption will continually grow while intensity declines. Thus, declines in intensity are not necessarily indicative of a move toward reductions in total consumption. It is noteworthy that the GDP coefficient is lowest in China and India, the two low-income nations, and highest in the United States, where it is close to unitary elasticity. This finding counters the common assumption that the most affluent nations will show the greatest improvements in ecological performance due to improvements in technological and other efficiencies as they continue to develop.

\section{CONCLUSION}

We examined trends in measures of human demands placed on nature's capital and services as indicated by three different forms of the EF - total, per capita, and per unit of GDP (intensity) - in China, India, Japan, and the United States. We found that the EF intensity of each nation's economy declined between 1961 and 2003 (i.e., the economies became more efficient in the sense that they each got more economic output per unit of EF). However, interpreting this trend as an environmental improvement is misleading because the total footprint of all four nations rose substantially over this four-decade period. Furthermore, the per capita footprint approximately doubled in China, Japan, and the United States over this period, while it remained roughly constant in India. In time-series analyses of the connection between GDP and the EF we found a positive inelastic relationship in all four nations, indicating that improvements in efficiency in each nation over this period were more than counter-balanced by increases in scale, leading the EF of each nation to grow. The key implication of these results is that improvement in efficiency is not a sign of progress toward sustainability but is paradoxically associated with increased threats to the environment.

The ecological fate of the world lies to a growing extent in India and, especially, China. Over the period examined here, China's total ecological footprint expanded four-fold to rival that of the United States. In fact, it appears that China, which builds a new coal power plant approximately every four days, has surpassed the United States to become the single largest emitter of carbon dioxide in the world (although the United States still emits much more carbon dioxide on a per capita basis) due to rapid growth in fossil fuel consumption and cement manufacturing in recent years (Cyranoski 2007; Liu and Diamond 2008). This has occurred while the carbon intensity of China's economy has declined dramatically (Fan et al. 2007), 
underscoring our key message here: improvements in efficiency typically do not lead to declines in environmental problems. In fact, in footprint terms China is looking more like a core nation since its footprint is larger than its land area. This is due in no small part to its vast and growing appetite for imports, such as fish, tropical wood, and manufactured goods, and to the embodied energy in these goods (Hong et al. 2007; Liu and Diamond 2005). Clearly, China's dramatic improvements in eco-efficiency and its stated commitment to tackling environmental problems have not translated into reductions in its global environmental impacts (Liu and Diamond 2008).

To achieve sustainability and avert environmental crisis the four nations we examined here and the world as a whole need to dramatically scale back their consumption of the Earth's resources. Affluent nations, like the United States and Japan, which have exceedingly high levels of per capita consumption, need to drastically reduce the demands they place on the environment and transform their political, economic, and social systems to meets people's needs without unsustainably devouring natural resources. Less affluent nations, such as China and India, need to shift their development strategies away from relentless economic expansion and focus on strategies that improve people's quality of life without escalating material consumption. It is important to note that such changes - reducing consumption in affluent nations and averting the excessive expansion of consumption in poor nations - do not necessitate inhibiting improvement of social well-being. There is ample evidence that material consumption, once beyond the level required to meet basic needs, does not have a strong association with human well-being. For example, Leiserowitz, Kates, and Parris (2005) note that in nations out of absolute poverty the association between economic development and the subjective well-being of people is very weak. Furthermore, Dietz, Rosa, and York (2007) found that there is no direct connection between environmental degradation and human well-being as measured by education and life expectancy. These findings suggest that we could further human development without worsening environmental quality if we shift our focus away from economic growth as the primary social goal and toward the enhancement of more direct features of well-being.

It is important to recognize that the size and growth of human population plays a major role in the expansion of impacts on the environment. For example, as we show here, while India's per capita EF remained roughly stable, its total EF more than doubled, tracking the growth in its population. Likewise, China has such a large total EF, rivaling that of the United States, despite still having a low per capita EF by global standards, because it has well over one billion people. Addressing the population problem can be an important part of a progressive political agenda aimed at improving quality of life since the most effective ways to reduce fertility rates include improving the status and education of women, reducing infant mortality, eliminating absolute poverty, and providing all people with access to safe, effective and affordable birth control (Cohen 1995). Thus, what is needed to reduce human impact on the global environment - the curtailing of overconsumption and the reduction of fertility rates - can be part of an agenda aimed at directly improving human quality of life.

In light of the continuing high levels of consumption in affluent nations, the rapid economic growth in many developing nations in recent years, and the severity of environmental problems the world faces - the most noteworthy of which may be global climate change averting ecological crisis is arguably humanity's greatest challenge for the twenty-first century. To meet this challenge it is imperative that we move away from the unrealistically optimistic assumption that improvements in the efficiency of economies alone are likely to solve 
environmental problems. In the face of continued economic and population growth, that assumption is not only misleading, it is also dangerous.

\section{Acknowledgement}

We thank Mathis Wackernagel and Brad Ewing for providing us with the data on ecological footprints analyzed in this article.

\section{REFERENCES}

Andersen, Mikael Skou. 2002. "Ecological Modernization or Subversion? The Effects of Europeanization on Eastern Europe.” American Behavioral Scientist 45(9):1394-1416.

Arrighi, Giovanni. 2004. "Spatial and Other 'Fixes' of Historical Capitalism.” Journal of WorldSystems Research 10(2):527-539.

Brunnermeier, Smita B. and Arik Levinson. 2004. Examining the Evidence on Environmental Regulations and Industry Location. Journal of Environment \& Development 13(1): 6-41.

Bunker, Stephen G. 1996. Raw Material and the Global Economy: Oversights and Distortions in Industrial ecology.” Society and Natural Resources 9:419-429.

Burns, Thomas J., Edward L. Kick, and Byron L. Davis. 2003. "Theorizing and Rethinking Linkages Between the Natural Environment and the Modern World-System: Deforestation in the Late $20^{\text {th }}$ Century." Journal of World-Systems Research 9(2):357390.

Chambers, Nicky, Craig Simmons, and Mathis Wackernagel. 2000. Sharing Nature's Interest: Ecological Footprints as an indicator of sustainability. London: Earthscan.

Clark, Brett and John Bellamy Foster. 2001. William Stanley Jevons and The Coal Question: an Introduction to Jevons's 'Of the Economy of Fuel.' Organization \& Environment 14(1):93-98.

Cohen, Joel E. 1995. How Many People Can the Earth Support? New York: W. W. Norton \& Co.

Cohen, Maurie J. 1997. "Risk Society and Ecological Modernization: Alternative Visions for Post-Industrial Nations.” Futures 29(2):105-119.

Cyranoski, David. 2007. "China Struggles to Square Growth and Emissions." Nature 446(26):954-955.

Dietz, Thomas and Eugene A. Rosa. 1997. "Effects of Population and Affluence on $\mathrm{CO}_{2}$ Emissions." Proceedings of the National Academy of Sciences of the USA 94:175-179.

Dietz, Thomas, Eugene A. Rosa, and Richard York. 2007. "Driving the Human Ecological Footprint.” Frontiers in Ecology and the Environment 5(1): 13-18.

Fan, Ying, Lan-Cui Liu, Gang Wu, Hsien-Tang Tsai, and Yi-Ming Wei. 2007. "Changes in Carbon Intensity in China: Empirical Findings from 1980-2003.” Ecological Economics 62(3-4):683-691.

Fisher, Dana R. and William R. Freudenburg. 2001. "Ecological Modernization and its Critics: Assessing the Past and Looking Toward the Future." Society and Natural Resources 14(8):701-709. 
Frey, R. Scott. 1998. "The Export of Hazardous Industries to the Peripheral Zones of the WorldSystem." Journal of Developing Societies 14:66-81.

2003. "The Transfer of Core-Based Hazardous Production Processes to the Export Processing Zones of the Periphery: The Maquiladora Centers of Northern Mexico.” Journal of World-Systems Research 9(2):317-354.

Grimes, Peter and Jeffrey Kentor. 2003. "Exporting the Greenhouse: Foreign Capital Penetration and $\mathrm{CO}_{2}$ emissions 1980-1996.” Journal of World-Systems Research 9(2): 261-275.”

Hawken, Paul, Amory Lovins, and L. Hunter Lovins. 1999. Natural Capitalism: Creating the Next Industrial Revolution. New York: Little, Brown and Company.

Hong, Li, Zhang Pei Dong, He Chunyu, and Wang Gang. 2007. Evaluating the Effects of Embodied Energy in International Trade on Ecological Footprints in China. Ecological Economics 62:136-148.

Hornborg, Alf. 2003. "Cornucopia or Zero-Sum Game? The Epistemology of Sustainability.” Journal of World-Systems Research 9(2): 205-216.

Jevons, William Stanley. 2001 [1865]. "Of the Economy of Fuel.” Organization \& Environment 14(1):99-104.

Jorgenson, Andrew K. 2003. "Consumption and Environmental Degradation: A Cross-National Analysis of the Ecological Footprint.” Social Problems 50: 374-394.

Jorgenson, Andrew K. and Thomas J. Burns. 2007. "The Political-Economic Causes of Change in the Ecological Footprints of Nations, 1991-2001.” Social Science Research 36: 834-853.

Jorgenson, Andrew K. and Edward L. Kick. 2003. "Globalization and the Environment.” Journal of World-Systems Research 9(2):195-203.

Jorgenson, Andrew K. and James Rice. 2005. "Structural Dynamics of International Trade and Material Consumption: A Cross-National Study of the Ecological Footprints of LessDeveloped Countries.” Journal of World-Systems Research 11:57-77.

Kitzes, Justin, Audrey Peller, Steve Goldfinger, and Mathis Wackernagel. 2007. "Current Methods for Calculating National Ecological Footprint Accounts." Science for Environment \& Sustainable Society 4:1-9.

Leiserowitz, Anthony A., Robert W. Kates, and Thomas M. Parris. 2005. "Do Global Attitudes and Behaviors Support Sustainable Development?” Environment 47(9): 23-38.

Liu, Jianguo and Jared Diamond. 2005. "China’s Environment in a Globalizing World.” Nature 435:1179-1186.

. 2008. "Revolutionizing China’s Environmental Protection.” Science 319: 37-38.

Loh, Jonathan and Steven Goldfinger. 2006. Living Planet Report 2006. Gland, Switzerland: WWF International.

Milanez, Bruno and Ton Bührs. 2007. "Marrying Strands of Ecological Modernisation: A Proposed Framework.” Environmental Politics 16(4):565-583.

Podobnik, Bruce. 2002. "Global Energy Inequalities: Exploring the Long-Term Implications.” Journal of World-Systems Research 8(2):252-274.

Reijnders, Lucas. 1998. “The Factor 'x' Debate: Setting Targets for Eco-Efficiency.” Journal of Industrial Ecology 2 (1):13-22.

Roberts, J. Timmons and Peter E. Grimes. 1997. "Carbon Intensity and Economic Development 1962-1991: A Brief Exploration of the Environmental Kuznets Curve." World Development 25:191-198. 
Roberts, J. Timmons, Peter E. Grimes, and Jodie L. Manale. 2003. "Social Roots of Global Environmental Change: A World-Systems Analysis of Carbon Dioxide Emissions." Journal of World-Systems Research 9(2):277-315.

Rosa, Eugene A., Richard York, and Thomas Dietz. 2004. "Tracking the Anthropogenic Drivers of Ecological Impacts.” Ambio 33(8):509-512.

Rothman, Dale S. 1998. “Environmental Kuznets Curves — Real Progress or Passing the Buck?” Ecological Economics 25:177-194.

Wackernagel, Mathis, Larry Onisto, Patricia Bello, Alejandro Callejas Linares, Ina Susana Lopez Falfan, Jesus Mendez Garcia, Ana Isabel Suarez Guerrero, and Ma. Guadalupe Suarez Guerrero. 1999. "National Natural Capital Accounting with the Ecological Footprint Concept.” Ecological Economics 29:375-390.

Wackernagel, Mathis and William Rees. 1996. Our Ecological Footprint: Reducing Human Impact on the Earth. Gabriola Island, B.C: New Society Publishers.

Wackernagel, Mathis, Niels B. Schulz, Diana Deumling, Alejandro Callenjas Linares, Martin Jenkins, Valerie Kapos, Chad Monfreda, Jonathan Loh, Norman Myers, Richard Norgaard, and Jorgen Randers. 2002. "Tracking the Ecological Overshoot of the Human Economy.” Proceedings of the National Academy of Sciences of the USA 99(14):92669271.

York, Richard. 2007. "Structural Influences on Energy Production in South and East Asia, 19712002.” Sociological Forum 22(4):532-554.

York, Richard. 2006. "Ecological Paradoxes: William Stanley Jevons and the Paperless Office.” Human Ecology Review 13(2):143-147.

York, Richard and Eugene A. Rosa. 2003. "Key Challenges to Ecological Modernization Theory: Institutional Efficacy, Case Study Evidence, Units of Analysis, and the Pace of EcoEfficiency." Organization \& Environment 16(3):273-288.

York, Richard, Eugene A. Rosa, and Thomas Dietz. 2004. "The Ecological Footprint Intensity of National Economies.” Journal of Industrial Ecology 8(4):139-154.

York, Richard, Eugene A. Rosa, and Thomas Dietz. 2003. "Footprints on the Earth: The Environmental Consequences of Modernity." American Sociological Review 68(2):279300 . 